\title{
Observed Volume of Distribution Normalized by Dose
}

National Cancer Institute

\section{Source}

National Cancer Institute. Observed Volume of Distribution Normalized by Dose. NCI

Thesaurus. Code C102683.

The volume of distribution associated with the terminal slope following intravascular administration, calculated using the observed value of the last non-zero concentration, divided by the dose. 